\title{
TEM and XRD determination of crystallite size and lattice strain as a function of illite crystallinity in pelitic rocks
}

\author{
W.-T. JIANG, ${ }^{1}$ D. R. PEACOR, ${ }^{2}$ P. ÁRKAI, ${ }^{3}$ M. TÓTH ${ }^{3}$ AND J. W. KIM ${ }^{2}$ \\ ${ }^{1}$ Department of Earth Sciences, National Cheng Kung University, Tainan, Taiwan 70101, ROC. \\ E-mail: atwtj@sparc3.cc.ncku.edu.tw \\ ${ }^{2}$ Department of Geological Sciences, The University of Michigan, Ann Arbor, Michigan 48109-1063, USA \\ ${ }^{3}$ Laboratory for Geochemical Research, Hungarian Academy of Sciences, H-1112 Budapest, Budaörsi út 45, Hungary
}

\begin{abstract}
Average crystallite size and mean-square strain of illite in rock specimens and clay separates were measured independently in TEM images and by single-line Fourier (Voigt method) profile analysis of the $c .1 \mathrm{~nm}$ peak of XRD patterns for a prograde sequence of pelitic rocks (illite crystallinity indices $=0.17-0.58^{\circ}$ D 2h) from the Gaspé Peninsula, Quebec. The TEM-determined crystallite sizes in clay separates approximate those determined by Fourier profile analyses and those calculated from illite crystallinity indices by the Scherrer equation, with the exception of the diagenetic sample. The crystallite sizes and mean-square strains of illite in rock samples exhibit a trend similar to that determined by profile analyses, but the average crystallite sizes are up to five times larger than those measured for clay separates.

TEM images show that all rock samples have a wide range of crystallite sizes, and the proportions of larger crystallites increase with metamorphic grade. The diagenetic illite is defect-rich, fine-grained (mean thickness by volume $=c .70 \mathrm{~nm}), 1 M_{\mathrm{d}}$ material. Anchizonal illite tends to occur as separate aggregates of small $1 M_{\mathrm{d}}$ and larger $2 M_{1}$ crystals $(c .200 \mathrm{~nm})$, comprising arrays of subparallel coalescing packets. The epizone sample has thick $(c .400 \mathrm{~nm})$, defect-free crystals of muscovite occurring in stacks of parallel layers, or subhedral crystals intergrown with large-angle boundaries. Cleaved crystals that are free of intracrystalline layer terminations are dominant in clay separates of all samples, having ranges of smaller sizes with volume-average thicknesses of c. 43, 43, and $81 \mathrm{~nm}(c .14,28,67 \mathrm{~nm}$ by the Voigt method), respectively, for the three zones.

The results suggest that illite crystallinity indices do not provide a direct measure of a single microstructural state of illite in rocks, although they yield consistent limits for average crystallite sizes for the anchizone ( $23 \& 48 \mathrm{~nm}$ here). Therefore, they serve as a general parameter of the degree of recrystallization on a relative basis, in part because the contributions of all peak-broadening variables (mixed layering, size and strain) decrease regularly with prograde regional metamorphism of pelites. The microstructural changes caused by rock disaggregation are probably a function of those variables as well. The data collectively demonstrate a trend from metastable, defect-rich, small crystals towards a stable assemblage of larger, defect-free crystals, through dissolution of strained crystals and neocrystallization, consistent with the Ostwald step rule.
\end{abstract}

Key words: crystallite size; illite crystallinity; lattice strain; TEM; XRD.

\section{INTRODUCTION}

Numerical measurements of changes in the peak profiles of illite basal XRD reflections as a function of grade of diagenesis and low-grade metamorphism were first proposed approximately three and a half decades ago (Weaver, 1960, 1961). Kübler (1967) used the halfheight peak width of the $c .1 \mathrm{~nm}$ reflection as a measure of the crystallinity of illite. It is therefore referred to as the illite crystallinity (IC) index, or the Kübler index. The value of the IC index decreases as the crystallinity increases, concurrent with an increase of the degree of diagenesis and incipient metamorphism (for reviews, see Kisch, 1987; Frey, 1987). Depending upon the timing of crystallization, dissolution and neocrystalliz- ation, and deformation, IC has been observed to increase with deformation in several sedimentary sequences (e.g. Frey et al., 1973; Roberts \& Merriman, 1985; Aldahan \& Morad, 1986), whereas no enhancement has been observed in other cases (e.g. Flehmig \& Langheinrich, 1974; Teichmüller et al., 1979; Nyk, 1985).

Frey (1987) reviewed the variables that affect the values of IC. They include temperature, fluid pressure, stress, duration of peak burial diagenetic or metamorphic conditions, lithology, illite composition, the presence of other micaceous minerals, sample preparation, and instrumental conditions. The effects of most of those variables were inferred from correlations with the nature and history of studied rocks rather than from the relations between directly observed chemical, 
textural and structural states of illite as compared with IC. A detailed characterization of progressive changes in illite is critical to an understanding of the origins of prograde variations in IC. Geological variables can then be correlated with the specific features of illite leading to changes in the index, and thus the index can be utilized in a more quantitative fashion.

IC is considered to be primarily a function of crystallite size and imperfection (strain), and it is therefore a measure of conditions of formation (Kodama, 1965; Kodama et al., 1971; Árkai \& Tóth, 1983; Lee et al., 1985, 1986; Merriman et al., 1990; Nieto \& Sánchez-Navas, 1994). Although Merriman et al. (1990) utilized the Scherrer equation to relate TEM-measured and XRD-determined crystallite sizes, that equation does not consider the effect of strain. There have been no quantitative correlations with direct measurements of both crystallite size and lattice strain. The presence of lattice imperfections created during crystal growth or recrystallization of illite during various stages of metamorphism and deformation is well known, however (Bons, 1988 \& references therein). The neglect of the contribution of such strain to IC causes that effect to be inaccurately accorded to crystallite size. Crystallite sizes thus determined are therefore too small. It is therefore essential that strain be considered in the determination of the origins of IC indices.

In studying illite in pelites, Merriman et al. (1990) and Nieto \& Sánchez-Navas (1994) suggested that the mode values of crystallite sizes determined by TEM correlate better with the Scherrer crystallite sizes than do the mean values. The mean and mode values of TEM-measured crystallite thicknesses reported in those two studies were calculated on the basis of the numbers of crystallites, unweighted by volume. However, the Scherrer equation was derived on the basis of volumeweighting, so good correlations between numbers of crystallites of a given size as determined by XRD, and those determined by TEM, are only fortuitous.

With the exception of Merriman et al. (1990) and Nieto \& Sánchez-Navas (1994), TEM measurements have been made on 'separates', i.e. samples that have been physically disarticulated (e.g. Inoue et al., 1988; Lanson \& Champion, 1991). However, although Nieto \& Sánchez-Navas (1994) used separates for mudstone samples and ion-milled samples for slates, no comparison between the two types of samples was made. Cleavage and biases in the sampling of separates must give rise to differences in crystallite size distributions of separates and original rock samples. It is therefore essential that TEM measurements of crystallite thickness be obtained and compared for samples as they occur in clay separates and in original rocks. Those parameters can then be compared with thicknesses determined by peak-profile analyses of XRD samples, as determined for separates.

XRD peak profiles are convolutions of various breadth functions such as lattice distortions, crystallite sizes and instrumental factors (Klug \& Alexander, 1974). Warren-Averbach Fourier analysis (Warren \& Averbach, 1950) and Wilson's variance method (Wilson, 1962, 1963a) are two of the methods commonly used to analyse lattice strain and mean crystallite size. Kodama (1965) and Kodama et al. (1971) analysed peak profiles of the $00 l$ reflections of sericite and muscovite by the Warren-Averbach method, showing that broadening of sericite and muscovite $00 l$ reflections was caused not only by small crystallite sizes but also by crystal defects or structural disorder involving variable interlayer spacings. Árkai \& Tóth (1983) described an increase of crystallite size concomitant with a decrease in lattice strain in a prograde series of pelites from northeast Hungary, utilizing the variance method. Eberl \& Srodon (1988) used both Fourier analysis and TEM Pt-shadowing techniques to obtain illite crystallite thicknesses along $c^{*}$, assuming that crystallite size and swelling layers were the principal contributions to peak shape. The studies described above did not include direct measurements of lattice distortion and provided no relation to crystallite sizes in unseparated rock samples.

The above discussion of previous work therefore shows that the following three kinds of relations must be obtained and compared in order to arrive at a quantitative relation between IC and geological parameters: (1) quantification of both crystallite size and lattice strain through XRD profile analysis, (2) correlation of TEM-measured and XRD-determined crystallite size and strain, considering correct interpretations of weighting, and (3) correlation of microstructural states of illite in clay separates (i.e. XRD samples) and rocks, and IC as a function of metamorphic grade. Those relations are quantified in this study. Both crystallite sizes (thicknesses) and defect densities of illite have been directly measured using TEM images of ion-milled pelites from a prograde sequence in the Gaspé Peninsula, Quebec. Crystallite sizes of illite in clay separates of the same samples as those used in XRD work were also measured by TEM. The Voigt method (Langford, 1978; de Keijser et al., 1982) was used to analyse XRD line profiles to derive illite crystallite size and strain. The resultant measures of strain and mean crystallite size are directly compared with TEM-determined values.

\section{SAMPLE DESCRIPTIONS}

A prograde sequence of pelitic rocks from the Taconic orogenic belt of the Gaspé Peninsula was kindly provided by R. Hesse. This pelitic sequence was well characterized by Islam et al. (1982), Islam \& Hesse (1983) and Hesse \& Dalton (1991) using IC, percentage of $2 M$ dioctahedral mica polytype, reflectance of organic matter, fluid inclusions, conodont colour alteration index, and clay-mineral assemblages. The samples were chosen to cover as large a range of IC as possible within a continuous prograde metamorphic 
sequence. The only dioctahedral phyllosilicates are the illite/muscovite series $(\mathrm{Na}$ content $<5 \%$ total interlayer charge), with only minor smectite in lowgrade samples (Jiang \& Peacor, 1994a). Values of IC therefore have no contribution from other $c .1 \mathrm{~nm}$ phyllosilicates.

The samples are Ordovician deep-marine sediments from the Deslandes and Cloridorme formations of basin-floor turbidites, which formed in a complex foreland basin created in the early stages of the Taconic orogeny, and were later deformed in that orogeny (St. Julien \& Hubert, 1975; Williams \& Hatcher, 1983). Dynamothermal metamorphism was completed at c. $440 \mathrm{Ma}$. A granitic to granodioritic pluton was subsequently emplaced during the late Devonian (Whalen, 1985). Islam et al. (1982) observed a regional pattern with a local increase in grade towards the pluton due to contact metamorphism, superimposed on a regional northward increase of metamorphic grade with decreasing rock ages in the area east of the pluton. The studied samples are from the diagenetic zone (A419 \& A416), anchizone (R297, R298, R299, 89-12 \& R237) and epizone (R245 \& R246), and were obtained in a traverse along the northern coast of the region east of the pluton. Detailed sample localities and descriptions are given by Jiang \& Peacor (1994a). Maximum estimated temperatures range from $c .80^{\circ} \mathrm{C}$ in the diagenetic zone to $c .260{ }^{\circ} \mathrm{C}$ in the epizone based on fluid-inclusion data (Islam \& Hesse, 1983; Hesse \& Dalton, 1991).

Quartz, chlorite (or corrensite), illite (or muscovite) and albite are the principal minerals in all samples. The lowest-grade samples have a weakly defined bedding-parallel cleavage and the epizone rocks have two mutually perpendicular cleavages. The ratio $2 M_{1} / 1 M_{\mathrm{d}}$ of proportions of polytypes increases significantly from the diagenetic zone to the epizone, the $1 M_{\mathrm{d}}$ polytype being undetectable in the epizone (Hesse \& Dalton, 1991). The white mica varies from phengitic illite in the diagenetic zone to muscovite in the epizone (Jiang \& Peacor, 1994b).

\section{METHODS}

\section{X-ray powder diffraction}

Samples were initially hammer-crushed and gently reduced further using a mortar and pestle, with frequent use of sieving, following the procedures recommended by Kisch (1991). Slides of oriented $<2 \mathrm{~mm}$ fractions were prepared by a pipette method following the sedimentation of disaggregated samples in distilled water (Brindley \& Brown, 1984). All XRD patterns were established in ethyleneglycol solvated and air-dried $<2 \mathrm{~mm}$ fraction samples. A Philips XRG 3100 instrument was used with $\mathrm{CuKa}$ radiation at $35 \mathrm{kV}$ and $15 \mathrm{~mA}$ with a theta compensating slit with a maximum divergent angle of $1^{\circ}$, a receiving slit of $0.2 \mathrm{~mm}\left(c .0 .15^{\circ}\right)$, a Soller slit assemblage, a graphite crystal monochromator and a scintillation detector. A step size of $0.01^{\circ} \mathrm{D} 2 \mathrm{~h}$ and a counting time of $c .6 \mathrm{~s}$ were used. Quartz was used as an internal standard. Variations in halfheight peak widths among ten patterns recorded for each sample at different times are within $\pm 2 \%$ of the mean value.

\section{Transmission electron microscopy}

Four samples representative of the diagenetic zone, anchizone and epizone were selected for TEM observation. Images were obtained from the thin edges of carbon-coated, ion-milled specimens that were attached to $3 \mathrm{~mm}$ diameter Al washers. All selected areas were first determined to consist largely of matrix (i.e. authigenic) minerals by scanning electron microscopy. XRD samples were treated by encapsulating the glass slides and undisturbed powder within resin, with subsequent ion milling. A Philips CM12 scanning transmission electron microscope (operated at $120 \mathrm{kV}$ ) equipped with a Kevex Quantum detector oriented at a low angle for X-ray energy dispersive spectrometer analysis was used. Most lattice-fringe images were obtained with $00 l$ reflections $(d \geqslant c .4 .7 \mathrm{~nm})$ included within the objective lens aperture. Detailed instrumental settings and procedures were given by Jiang \& Peacor (1991) and Slack et al. (1992).

\section{X-ray powder diffraction profile analysis}

XRD line profiles can be expressed in the form of Fourier series. Each diffraction profile is a convoluted function of all specimen functions and instrumental aberrations. Specimen and instrumental functions can be separated by deconvoluting the profile function with the use of a reference profile obtained from a coarse-grained $\left(\geq c .10^{4} \mathrm{~nm}\right)$, strain-free material of the same structure and composition as the sample using Fourier transforms (Wilson, 1963b). The remaining profile is then a convolution of lattice distortion (strain) and mean crystallite size or size-distribution functions. Warren \& Averbach (1950) derived equations that relate the Fourier cosine coefficient of the power distribution of a pure profile to the crystallite size and strain components. Through the Warren-Averbach method, the mean-square strain and area-averaged crystallite size in a given material can be obtained by analysing specific reflections of two or more orders. Because higher-order peaks of poorly crystalline materials often are too broad or weak, or overlap with peaks of other phases, analysis of peak profiles using only first-order peaks based on the Voigt method has increasingly been used in recent years (e.g. Langford, 1978; Delhez et al., 1982; de Keijser et al., 1982). The method assumes that the Cauchy and Gaussian components of a line profile are due to size and strain broadening, and utilizes the integral breadths of the respective functions to obtain values of average crystallite size and mean square strain. The integral breadths can be obtained from a parabolic fit to the natural logarithms of the Fourier coefficients of the line profile.

Only c. $1 \mathrm{~nm}$ reflections of illite obtained using air-dried and ethylene-glycolated specimens were used in profile analyses in this study. A reference profile for corrections of instrumental broadening was obtained using a cleavage plate of pegmatitic muscovite, a type of standard that yields minimal instrumental broadening (Arkai et al., 1996). The profile analysis was carried out utilizing a programme developed in the Laboratory for Geochemical Research of the Hungarian Academy of Sciences. The programme has successfully been used to analyze crystallite size and lattice distortion of illite, showing results consistent with those obtained by other XRD-based calculations and TEM measurements (Árkai et al., 1996).

\section{TEM measurements of crystallite size and imperfection}

Crystallite size is defined as the dimension of a coherently diffracting domain in the direction perpendicular to the diffracting plane (Klug \& Alexander, 1974); that is, reflection occurs simultaneously throughout the domain. Size variations in other directions do not affect the diffraction relations for the plane of interest, but must be considered in integrating intensity. The term 'lattice imperfection' refers to residual strains and stacking faults. Stacking faults are normally parallel to the basal planes in phyllosilicates and do not affect basal reflections. Dislocations and plastic bending of layers are generally the principal expressions of residual strains affecting basal reflections of illite. Bending of crystals (dislocations with $\{h k 0\}$ half-planes and $\langle u v 0\rangle$ Burgers vectors) cannot be quantified simply 
by 001 lattice-fringe imaging. The calculation of lattice strain contributed by such imperfections is difficult and problematic because of a lack of knowledge of the degree of lattice relaxation and polygonization. Continuous but irregular curvature of layers also creates difficulties in determining the sizes of coherently diffracting domains. However, domains consisting of such imperfections only occupy a small volume relative to those having layer terminations (dislocations with $\{001\}$ half-planes and $\langle u v 0\rangle$ or $\langle 001\rangle$ Burgers vectors) or no imperfections as observed in our TEM work. Lattice strains due to crystal bending are therefore neglected in this study.

According to Guinier (1963), Wilson (1963b), and Klug \& Alexander (1974), mean crystallite sizes derived from peak breadths at half-maximum heights or integral breadths are average values weighted by domain volumes, not by numbers of domains. Measurements of dimensions from TEM images include the thickness parallel to $c^{*}$, the length parallel to the basal plane, and the number of dislocations in each domain of uniform thickness as observed in 001 lattice-fringe images. Each crystallite was divided into one or more domains, each having a constant thickness, because thickness often varies within a single crystallite. The average domain thickness along $c^{*},\langle T\rangle$, in each sample is given by

$$
\langle T\rangle=\sum_{i=1}^{N}\left(T_{i} V_{i} / V_{c}\right) \prod_{i=1}^{N}\left(V_{i} / V_{c}\right)=\sum_{i=1}^{N}\left(T_{i} V_{i}\right) \prod_{i=1}^{N} V_{i},
$$

where $T_{i}$ is the thickness of each measured domain along $c^{*}, V_{c}$ describes the volume of a hypothesized unit domain, $N$ represents the total number of measurements, and $V_{i}$ defines the domain volume giving a corresponding $T_{i}$, which can be calculated from the corresponding thickness parallel to $c^{*}$ and length parallel to the basal plane, assuming that each measured domain is a hexagonal plate resembling the crystal habit of mica. For example, for the domains shown in Fig. 1, the same coherent crystal would be represented by two hexagonal plates in our calculations. They are measured separately because they have different broadening effects on basal reflections.

The mean-square strain $\left\langle e^{2}\right\rangle$ of each sample can be approximated by

$$
\left\langle\mathrm{e}^{2}\right\rangle=\sum_{i=1}^{N}\left[\left(L_{i} / L_{c}\right)\left(10 D_{i} / T_{i}\right)^{2}\right] \prod_{i=1}^{N}\left(V_{i} / V_{c}\right)
$$

where $L_{i}$ and $L_{c}$ are the lengths of a measured domain and supposed unit domain parallel to the basal planes, respectively (Fig. 1), 10 is the spacing of the basal planes in $\AA$, and $D_{i}$ defines the number of dislocations in each measured domain. All the dislocations are assumed to extend throughout each modelled hexagonal domain.

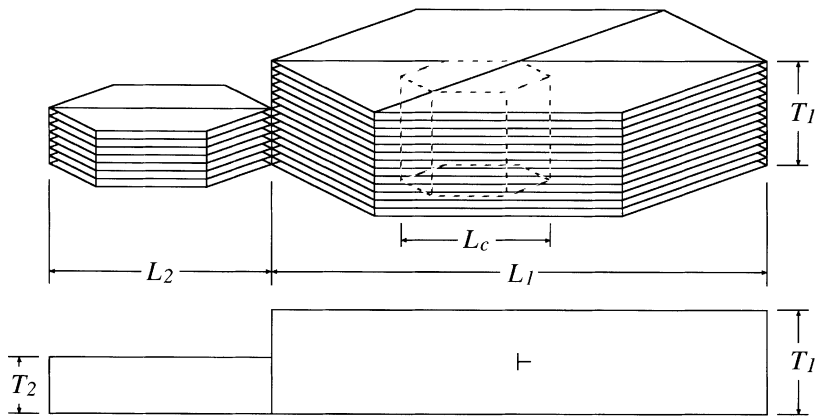

Fig. 1. Schematic diagram showing the relations among the measured parameters (length $L_{i}$ and thickness $T_{i}$ ), modelled hexagonal domains and dislocations, and hypothesized unit domains, with a three-dimensional view above and crosssections below. The horizontal lines on the surfaces of the hexagonal plates are the projections of the cross-sections shown in the lower portion of the figure. The intersection point of lines on the surface of the larger plate is a projection of the hypothesized trace of a dislocation, which is marked win the cross-section.
The ratio $L_{i} / L_{c}$ represents the total number of unit domains having a corresponding strain $10 D_{i} / T_{i}$ in a measured domain. The unit domain length (normal to $c^{*}$ ) $L_{c}$ is assigned to be $c .10 \mathrm{~nm}$ in this study, as layers in the vicinity of a dislocation are generally not distorted beyond this range, based on TEM observations. This approximation may overestimate the length of each dislocation but underestimate the number of dislocations because dislocations parallel to the image plane are not visible in 001 lattice fringes. This procedure can only yield relative magnitudes of strain, providing that the degree of lattice relaxation is constant in all samples.

The above model is an approximation and does not perfectly represent the true physical state of illite crystals in the samples. Observations of clay separates with basal planes oriented approximately normal to the electron beam indicated that clay crystals have irregular shapes in detail but are equant or round on average. The modelled hexagonal domains thus represent most crystals well, the irregular areas not included in the ideal shape representing only small portions of crystals. The model allows the desired factors to be represented by mathematically simple functions of measured parameters, but we emphasize that it represents only a first approximation. More precise calculations require a time-consuming measurement process that still must be based on questionable assumptions, and is therefore impractical at this time.

Intra- and intercrystal angular boundaries of various angles are encountered in TEM observations. Some angular boundaries have angles that are so small that related parts may be considered to be a coherently diffracting domain with intracrystal defects that are called 'angular imperfections' in X-ray crystallographic theory (Buerger, 1960). Reynolds (1989) described a treatment of diffraction from a finite plane that defines the intensity of diffraction as a function of the diffracting angle, the length of the finite plane, and the angle between the finite plane and the normal diffracting plane. The angular range that allows a finite plane to yield significant intensities in the diffracting angle and therefore to be treated as a part of the diffracting planes increases as the length of the finite plane decreases. For a plane $20 \mathrm{~nm}$ in length, the angular range that is allowed for a finite plane to deviate from the diffracting plane and to give significant intensities in the illite $1 \mathrm{~nm}$ reflection is $<2.9^{\circ}$. The diffraction relations concerning angular relations at boundaries observed in this study were determined following Reynolds' treatment.

\section{XRD PROFILES OF ILLITE BASAL REFLECTIONS}

The profiles of the illite basal reflections display prominent progressive changes in shape and halfheight width with increasing metamorphic grade (Fig. 2, Table 1). Repeated measurements on interlaboratory correlation samples deviated by $<4 \%$ from the accepted values of 0.38 and $0.21^{\circ} \mathrm{D} 2 \mathrm{~h}$ for the
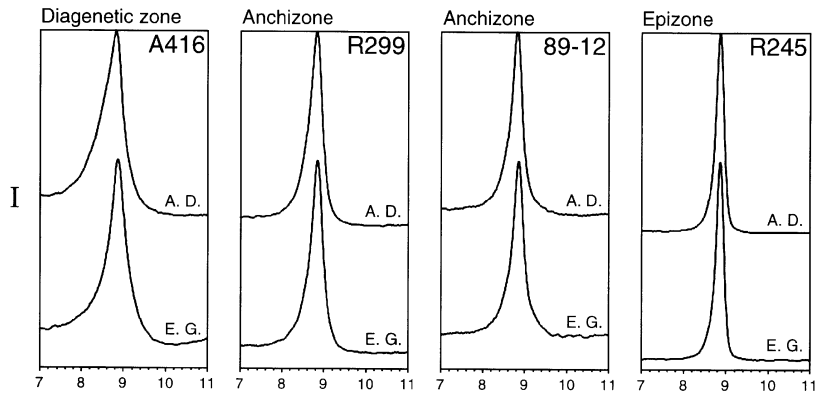

${ }^{\circ} 2 \theta$ (CuK $\alpha$ radiation)

Fig. 2. Peak profiles of the illite $c .1 \mathrm{~nm}$ peaks from X-ray powder diffraction patterns of oriented $<2 \mathrm{~mm}$ fractions of pelitic rocks from the Gaspé Peninsula, Quebec. A. D. and E. G. = air dried and ethylene glycolated, respectively. 
Table 1. Crystallinity indices, mean crystallite sizes and square roots of mean square strains of illite in the clay separates of the pelitic rocks from the Gaspé Peninsula, Quebec ${ }^{1}$.

\begin{tabular}{lcccc}
\hline Sample & $\begin{array}{c}\text { IC index } \\
\left({ }^{\circ} \mathrm{D} 2 \mathrm{~h}\right)\end{array}$ & $\begin{array}{c}\text { Crystallite size } \\
(\mathrm{nm})\end{array}$ & $\begin{array}{c}\text { SQRT of mean } \\
\text { square strain }(\%)\end{array}$ & Error $^{2}$ \\
\hline \multicolumn{2}{l}{ Air dried specimens } & & & \\
A419 & 0.69 & 9.5 & 2.30 & 0.074 \\
A416 & 0.58 & 13.9 & 1.75 & 0.038 \\
R297 & 0.42 & 21.7 & 0.99 & 0.014 \\
R298 & 0.34 & 24.5 & 1.06 & 0.025 \\
R299 & 0.36 & 27.3 & 0.83 & 0.013 \\
$89-12$ & 0.29 & 29.4 & 0.96 & 0.011 \\
R237 & 0.25 & 32.6 & 0.96 & 0.012 \\
R245 & 0.20 & 66.5 & 0.36 & 0.004 \\
R246 & 0.17 & 91.1 & 0.23 & 0.004 \\
& & & & \\
Ethylene-glycol-solvated specimens & & & \\
A419 & 0.58 & 13.8 & 1.36 & 0.080 \\
A416 & 0.45 & 18.5 & 0.97 & 0.030 \\
R297 & 0.36 & 23.8 & 1.02 & 0.014 \\
R298 & 0.31 & 26.1 & 0.92 & 0.011 \\
R299 & 0.32 & 27.3 & 1.06 & 0.015 \\
$89-12$ & 0.27 & 27.8 & 0.81 & 0.029 \\
R237 & 0.25 & 35.4 & 0.46 & 0.003 \\
R245 & 0.20 & 62.9 & 0.52 & 0.004 \\
R246 & 0.17 & 71.6 & & \\
\hline
\end{tabular}

${ }^{1}$ Mean crystallite size and square root of mean square strain were determined by Fourier single-line profile analyses of X-ray c. $1 \mathrm{~nm}$ reflections utilizing the Viogt method.

${ }^{2}$ Error $=$ the error of fitting a parabola to the natural logarithms of Fourier coefficients of the line profile devoid of instrumental broadening.

anchizone limits (Kisch, 1990) that were adopted in this study. The c. $1 \mathrm{~nm}$ reflection of sample A416 is slightly skewed toward the low $2 \mathrm{~h}$ side, implying the presence of a small proportion $(c .5 \%)$ of smectitic layers. Although this reflection became relatively symmetric after ethylene-glycol solvation, the proportion of smectitic layers could not be determined because higher-order peaks were weak and were obscured by other peaks, and there were no meaningful peak displacements. Coarse-grained detrital biotite occurs in sample A416 but is rare in separates.

\section{TEM OBSERVATIONS}

\section{Zone of diagenesis}

Small crystal sizes and high defect densities are characteristic of the diagenetic illite in sample A416. The illite commonly occurs as aggregates of coalescing packets of layers locally intergrown with chlorite and corrensite. Image contrast varies over short distances in all directions within a single packet of layers, lattice fringes being imaged over relatively small areas (Figs 3-5) compared to those in higher-grade rocks, implying a high degree of variability in layer orientation relative to the electron beam. Such crystal aggregates have an overall appearance similar to that of illite/smectite in Gulf Coast sediments (Ahn \& Peacor, 1986). However, the former consists of irregularly oriented bundles of parallel or subparallel packets of layers that are relatively thick compared to those contained in the

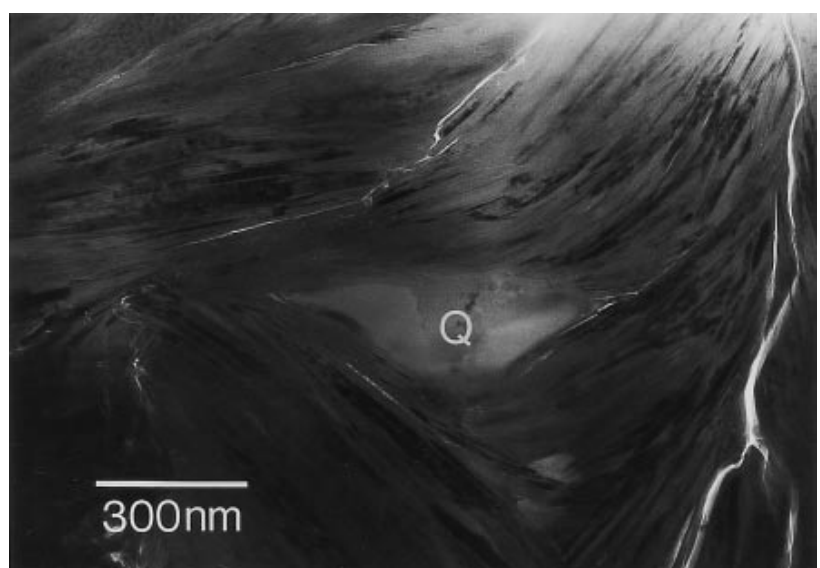

Fig. 3. Transmission electron microscope image of sample A416 of the diagenetic zone showing aggregates of illite packets surrounding a quartz grain (Q). Contrast variations occurring over short distances imply randomness in orientation.

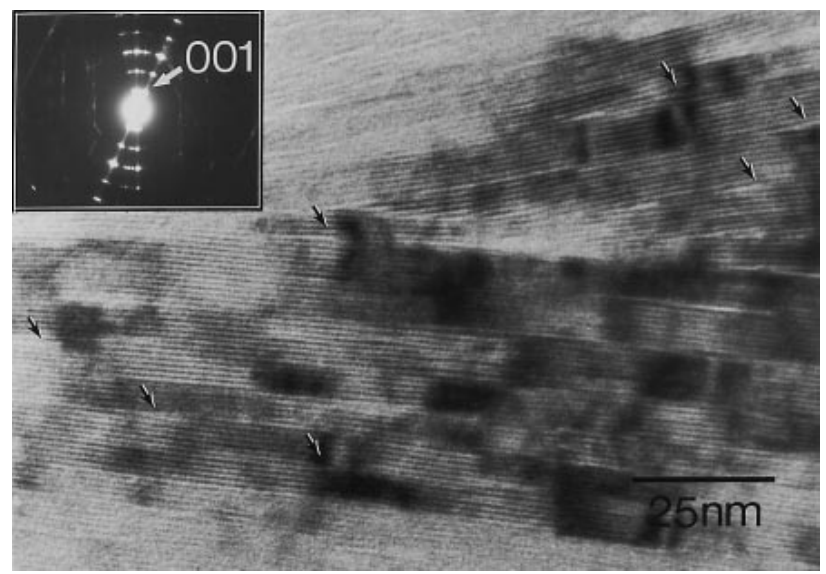

Fig. 4. Lattice-fringe image of thin packets of illite in diagenetic sample A416. The spacing of the layers is c. $1 \mathrm{~nm}$. Layer terminations are indicated by black arrows. The electron diffraction pattern of the area shows streaking along $c^{*}$ in non-00l reflection rows characteristic of $1 M_{\mathrm{d}}$ polytypism.

latter. Crystals as large as those in the anchizonal rocks occur only rarely, and the crystal population is dominated by small crystals.

Selected-area electron diffraction (SAED) patterns show diffuse, ill-defined, non-periodic, non-00l reflections, which are typical of the $1 M_{\mathrm{d}}$ polytype (Grubb et al., 1991). Although such SAED patterns do not have the continuously diffuse non-00l reflections characteristic of ideal $1 M_{\mathrm{d}}$ illite, and clearly consist of layers that are locally ordered, they are typical of stacks of illite or illite-rich I/S that have high densities of stacking faults and that are in their initial state of diagenetic formation.

The lattice-fringe images of $1 M_{\mathrm{d}}$ crystals commonly display layer terminations (Fig. 4) that are expressions of edge or screw dislocations. In some regions, orientations of individual layers are so variable that individual packets can hardly be defined (Fig. 5). These 


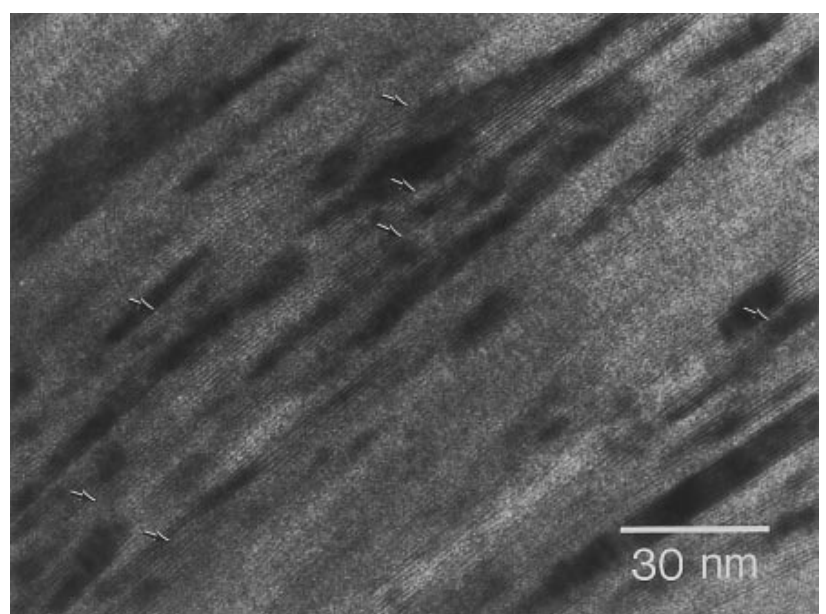

Fig. 5. Lattice-fringe image of illite in sample A416 of the diagenetic zone showing packets of layers that consist of domains having slightly different layer orientations and poorly defined boundaries. Layer terminations are highlighted with black arrows. The fringe spacing is $c .1 \mathrm{~nm}$.

features are collectively characteristic of poorly crystalline, immature material that may have been precursor to the thin but relatively defect-free illite crystals found in the same sample and imaged in Fig. 4. Although illite occurs most commonly in sample A416 as arrays of packets of layers (Figs $4 \& 5$ ), illite crystals with euhedral or subhedral outlines occur intergrown with quartz, chlorite or albite.

\section{Anchizone}

The anchizonal illite shows greater variation in texture than those of other grades in the same sequence, ranging from random aggregates of small crystals to bundles of subparallel, thicker packets of layers. Large

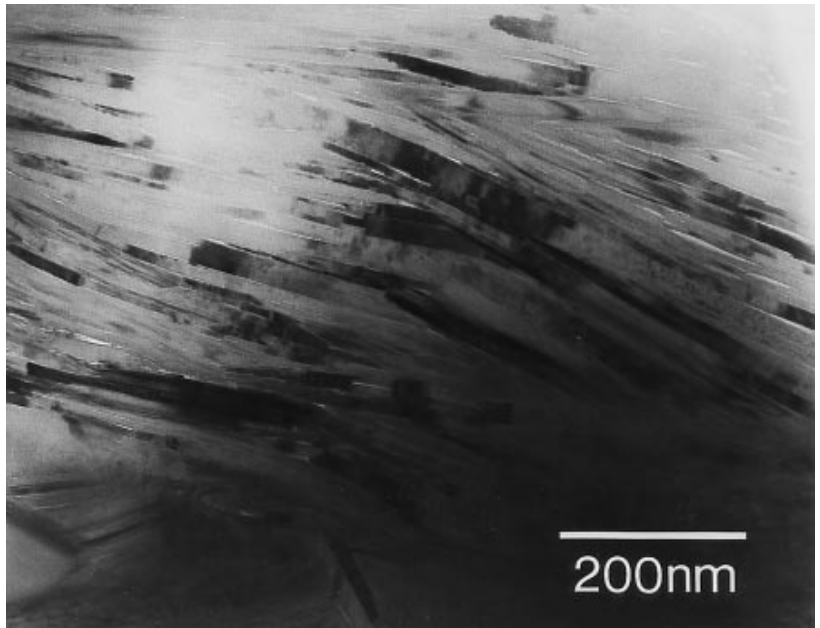

Fig. 6. TEM image of illite aggregates consisting of subparallel packets of layers in sample 89-12 of the anchizone. Each packet has uniform contrast over a relatively large area compared with those in the diagenetic sample. areas more commonly have continuous, constant contrast for large numbers of adjacent fringes (Fig. 6), implying a decrease in variability of crystal orientation. Layer terminations exist but the proportion of such imperfections is small compared to the diagenetic sample. Aggregates of relatively large, subparallel packets of illite are more common, but aggregates of small crystals occur as well. Small crystals have a relatively high defect density and are largely $1 M_{\mathrm{d}}$. They are similar to packets of diagenetic illite, except that their outlines are generally well defined (Fig. 7). Aggregates of parallel or subparallel, medium-sized crystals displaying two-layer polytypism occur commonly in the anchizonal samples, with dislocations occurring only locally (e.g. Fig. 8). No $2 M_{1}$ illite crystals were observed that are smaller than $10 \mathrm{~nm}$,

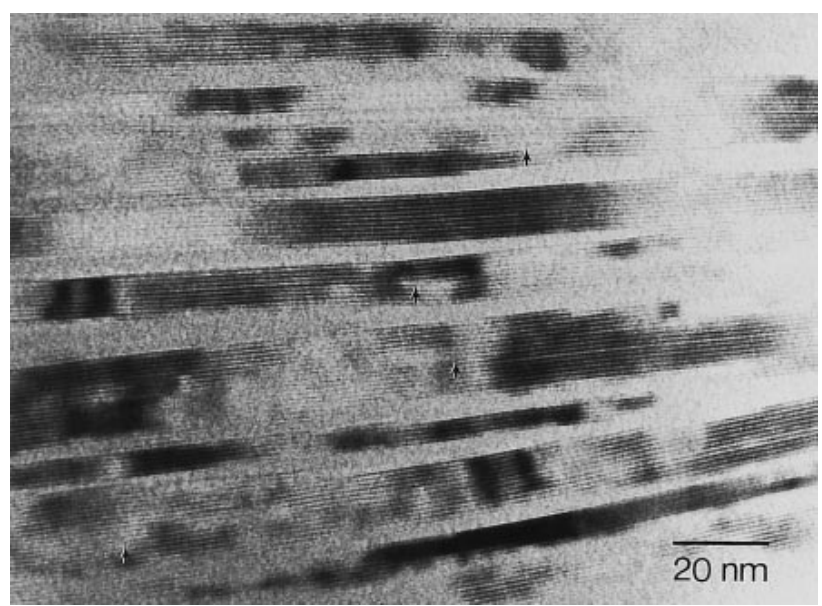

Fig. 7. Lattice fringes $(d=c .1 \mathrm{~nm})$ of illite in anchizone sample R299 showing aggregates of thin crystals similar to those in the diagenetic sample, but with relatively straight layers and betterdefined crystal boundaries. Black arrows point to layer terminations.

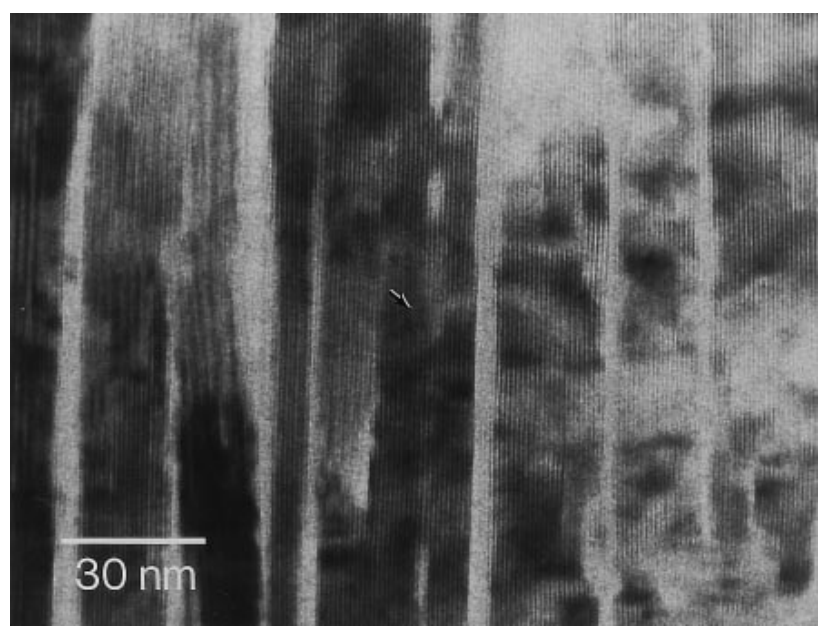

Fig. 8. Lattice fringes $(d=c .1 \mathrm{~nm})$ of intermediate-sized illite forming a thick stack of layers in sample R299 of the anchizone. Two-layer $(c .2 \mathrm{~nm})$ periodicity is present on the left, consistent with $2 M_{1}$ polytypism. 

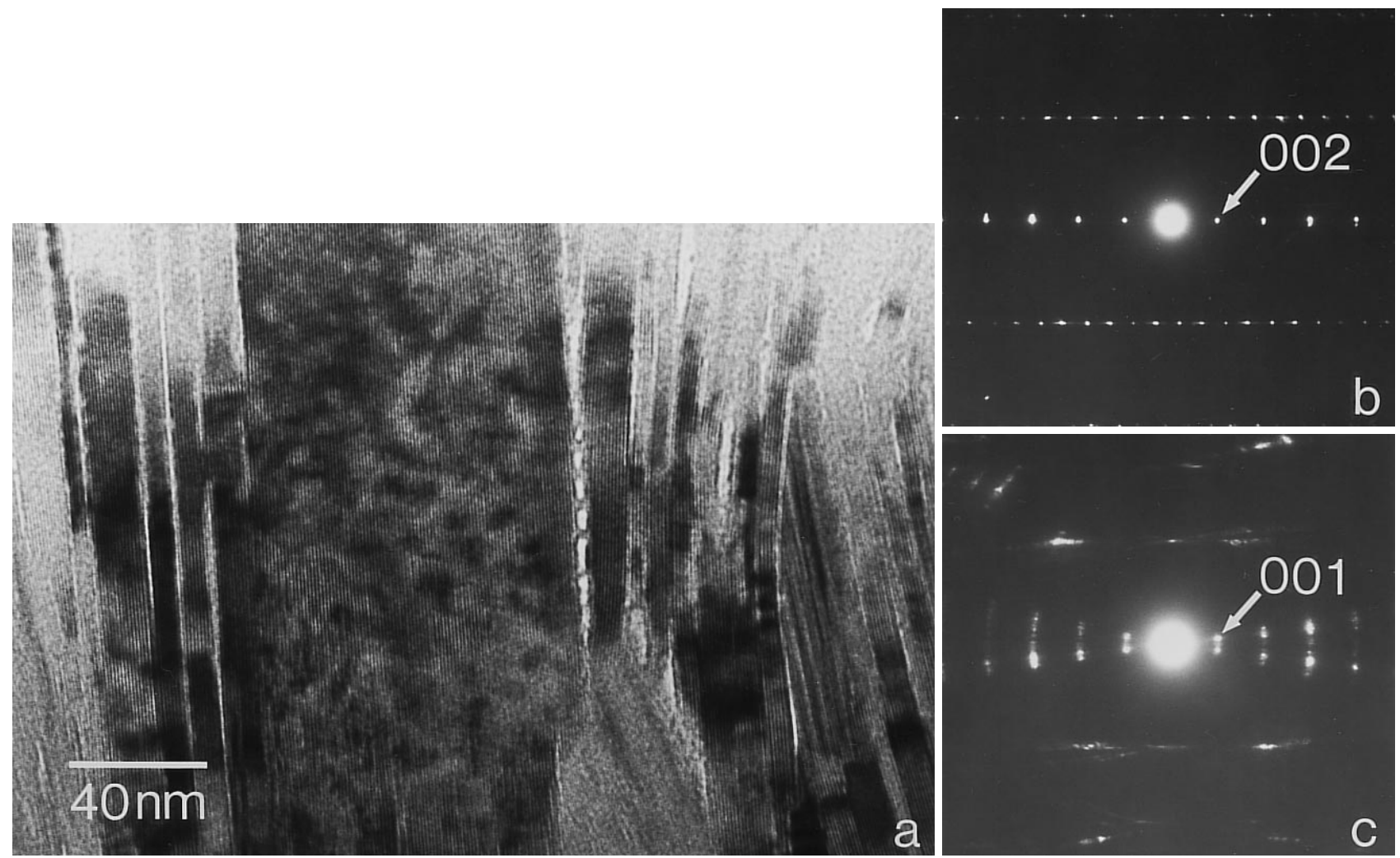

Fig. 9. (a) Lattice-fringe image of an intergrowth of coarser-grained illite (muscovite) (in the middle) and fine-grained illite (on either side) in sample 89-12 of the anchizone. (b) and (c) Electron diffraction patterns obtained from the muscovite and illite in (a) showing two-layer periodicity and streaking in the non- $00 l$ reflection rows characteristic of $2 M_{1}$ and $1 M_{\mathrm{d}}$ polytypism, respectively. $d(002)=c .1 \mathrm{~nm}$ in $(\mathrm{b}) ; d(001)=c .1 \mathrm{~nm}$ in $(\mathrm{c})$.

and no $1 M_{\mathrm{d}}$ polytype illite packets were observed to be larger than $60 \mathrm{~nm}$ in thickness.

Most small $1 M_{\mathrm{d}}$ and large $2 M_{1}$ illite crystals cluster in separate aggregates. However, some large $2 M_{1}$ illite (muscovite) crystals are intergrown with small subparallel packets of $1 M_{\mathrm{d}}$ illite (Fig. 9). Small crystals in such intergrowths typically have defects and show textures and electron diffraction patterns similar to those of diagenetic $1 M_{\mathrm{d}}$ illite. Some small but relatively defect-free crystals in such aggregates occur as parallel packets of layers that show different linear contrasts along layers and appear to merge to form large crystals (e.g. the middle left of Fig. 9a). Such crystals give c. $2 \mathrm{~nm}$ periodicity and weak streaking along $c^{*}$ in electron diffraction patterns, consistent with two-layer polytypism with local stacking faults. This type of diffraction pattern was observed commonly in aggregates of medium-sized illite crystals. These features collectively imply neoformation of $2 M_{1}$ illite.

A common feature of anchizonal samples is the lateral coalescence of packets of illite layers; that is the layers of two subparallel packets gradually become more parallel along-layer, ultimately merging as a single packet (Fig. 10). Intra- and intercrystal lowangle boundaries and layer terminations are associated with coalescing packets. Inclusions of other minerals such as chlorite are common. These features imply a stage of readjustment of boundaries of smaller packets of layers, forming large crystals (Fig. 10). The occurrence of a wide range of textures in the anchizonal rocks implies an intermediate stage of microstructural readjustment characterized by a variety of crystal growth mechanisms.

\section{Epizone}

The epizonal illite (muscovite) is dominated by large crystals of $2 M_{1}$ polytype. It typically occurs as thick packets of layers having well-defined boundaries, lacking or with few strain features. Such packets are intergrown in two ways, each of which is uncommon in lower-grade samples, i.e. they occur in parallel packets, each of which is well-defined, and which comprise thick stacks in the aggregate (Fig. 11), or they are related by interlocking relations and highangle boundaries (Fig. 12). These collective features, when compared to those of the anchizone, imply formation and migration of high-angle boundaries at the expense of strain in subparallel packets. Mediumsized $2 M_{1}$ illite crystals occur but are uncommon, 
Fig. 10. (a) TEM image of a thick stack of subparallel packets of illite layers surrounding a packet of chlorite layers $(\mathrm{C})$ and having low-angle boundaries (marked with open arrows) associated with layer terminations (dislocations) in sample 89-12 of the anchizone; (b) lattice fringes of part of (a) showing layer terminations (highlighted with black arrows).
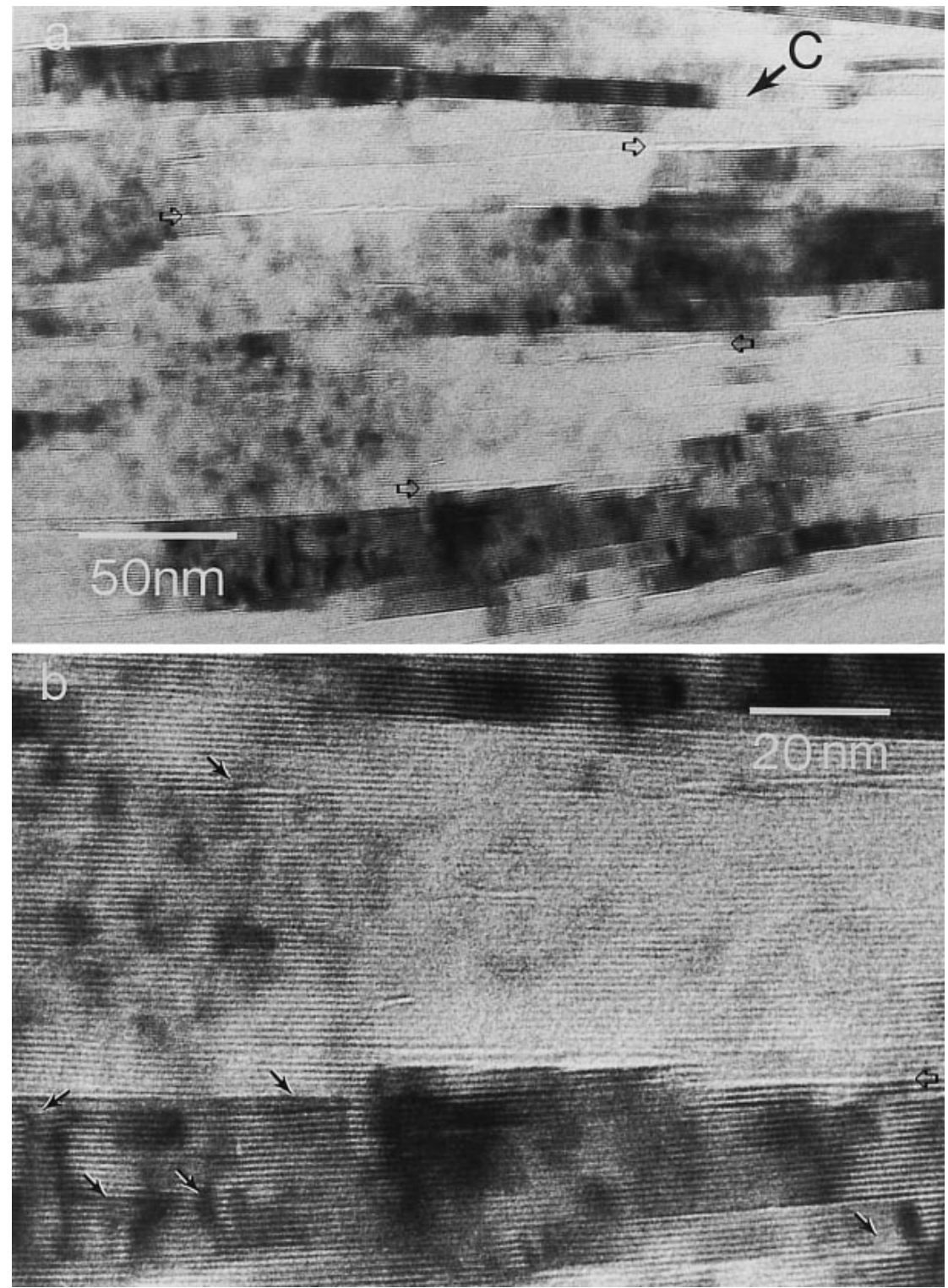

typically have euhedral shapes, and are enclosed within chlorite, quartz or albite.

\section{Clay separates}

The clay separates of samples A416, R299, 89-12 and R245 for XRD analysis have three features in common: (1) crystals are defect-free relative to those in ionmilled rock samples; (2) most crystals have sharply defined parallel or subparallel boundaries (Fig. 13a); and (3) many crystals exhibit the effects of $\{001\}$ cleavage (Fig. 13b). However, measured illite crystallite dimensions increase with increasing grade of sample, as do those of ion-milled rock samples, albeit with very different absolute magnitudes.

\section{CRYSTALLITE SIZE DISTRIBUTIONS AND LATTICE STRAIN MEASUREMENTS}

\section{Crystallite size distributions of illite in rock samples}

The crystallite size distributions of illite illustrated in Fig. 14 show that diagenetic illite is clearly dominated by domains of small thicknesses. The patterns of anchizonal samples R299 and 89-12 suggest a significant spread of the distribution profile towards larger thicknesses. In the epizonal sample there are no apparent concentrations of domain sizes, but there is a trend towards greater numbers of thicker crystallites. In general, the crystallite size distributions shown in Fig. 14 have skewed profiles with amplitudes that shift to greater thicknesses, lower amplitudes and increasing skewnesses towards large crystal thicknesses. 

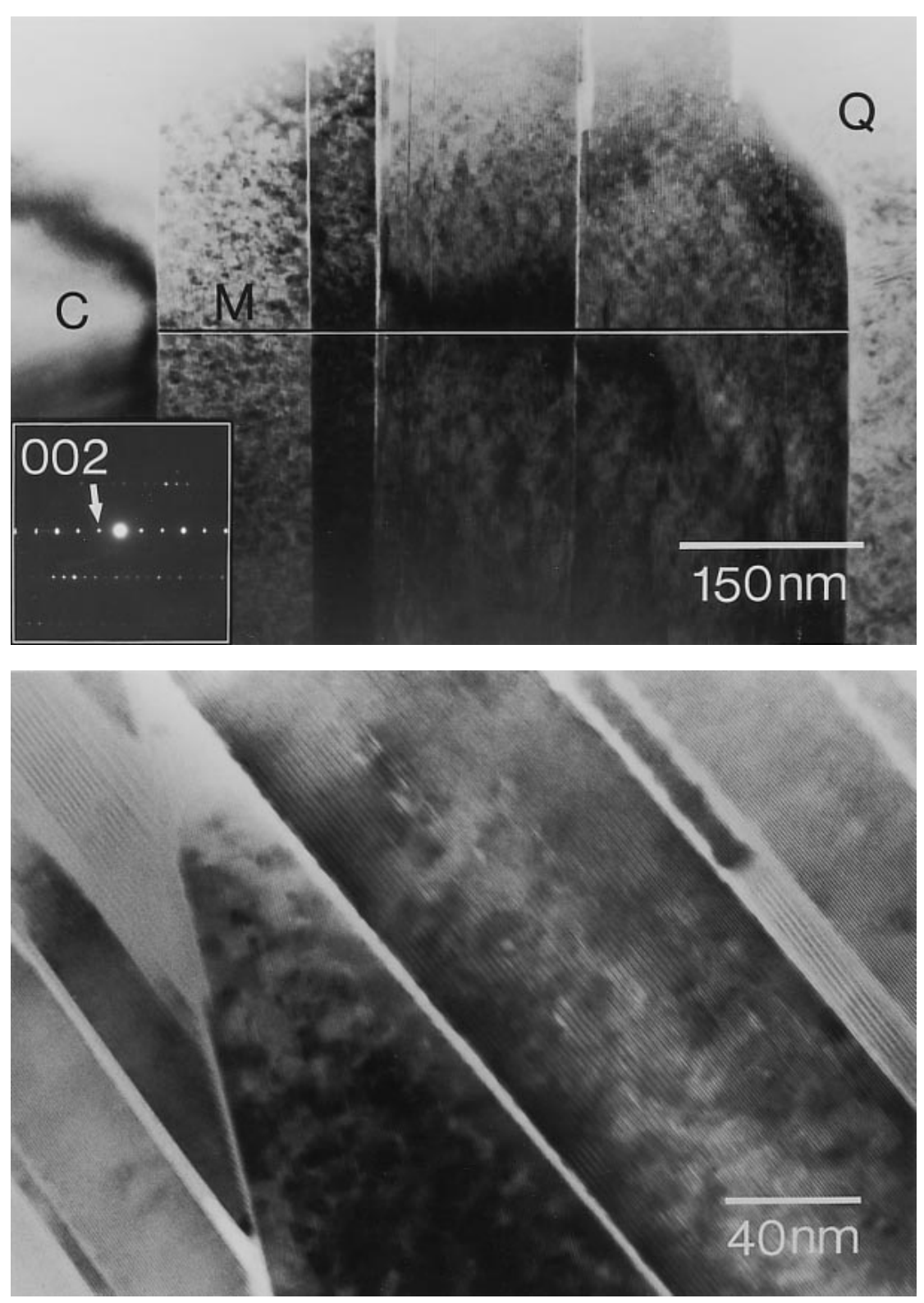

Fig. 11. TEM image of thick, parallel muscovite packets $(\mathrm{M})$ adjacent to quartz $(\mathrm{Q})$ and chlorite $(\mathrm{C})$ in sample R245 of the epizone. The corresponding electron diffraction pattern shows twolayer periodicity in $11 \mathrm{l}$ rows, consistent with $2 M_{1}$ polytypism.
These data demonstrate a significant increase of crystallite size with increasing grade, although they do not represent size populations in terms of numbers of crystallites. All of the size distributions have irregular profiles that do not correspond to any simple functions, although there are concentrations of high populations in certain ranges of sizes. The normalized thickness/ mean-thickness versus frequency/maximum-frequency diagrams (not shown) that are commonly utilized to study growth mechanisms (e.g. Eberl et al., 1990) therefore have irregular shapes that do not correspond to simple functions. The unevenness of the distribution profiles is probably in part caused by the lack of a sufficiently large number of measurements, an especially prominent relation for sample R245, in which crystallite sizes and the size distribution range are large and averaged only with difficulty. Sample 89-12 appears to contain two populations of crystallites with different ranges of thicknesses that give rise to the irregularity in the thickness distribution profile. Nevertheless, the general features are evident: the size distribution is spread over a larger range towards larger crystallites as the degree of diagenesis/metamorphism increases, and no single maximum and modal distribution can adequately characterize any of the patterns, in contrast, for example, to the analyses of illite and other minerals by Merriman et al. (1990) and Eberl et al. (1990).

\section{Crystallite size distributions of illite in clay separates}

The sizes of illite crystallites in clay separates are significantly smaller than those of rock samples (Fig. 15). The average sizes are up to five times smaller 


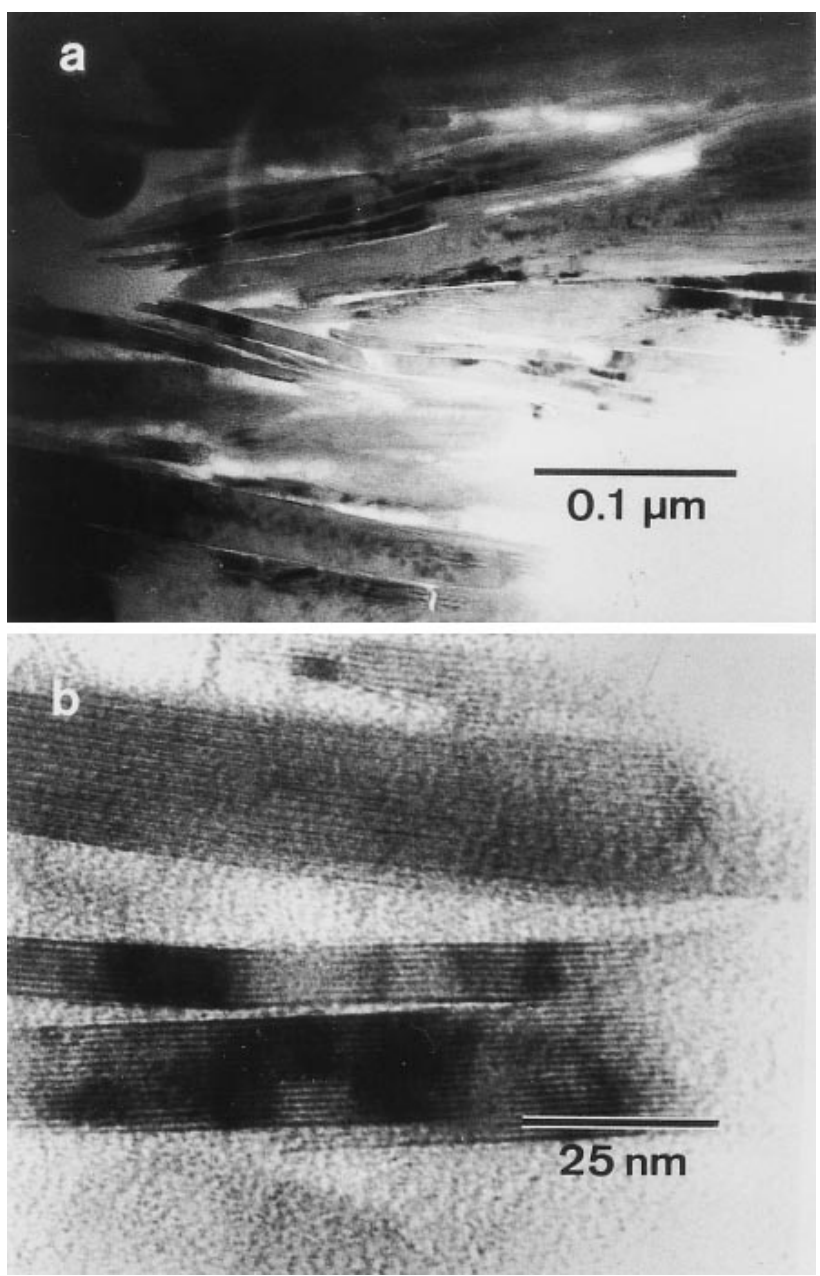

Fig. 13. TEM images of clay separates illustrating (a) well defined, clear-cut, parallel or subparallel boundaries among illite crystals in sample 89-12 of the anchizone, and (b) textures of a crystal being cleaved along layers in sample A416 of the zone of diagenesis.

(Table 2), although the trends of increasing size with metamorphic grade are similar. Densities of layer terminations were not measured from images of the separates used for XRD, in part because the number of observations was too small to be significant, but primarily because the very small numbers of layer terminations give rise to a vanishingly small contribution to strain.

\section{Comparison with XRD results}

The mean crystallite sizes from TEM imaging and XRD profile analysis are listed in Tables 1 and 2. For the same samples, the mean crystallite sizes of illite measured on clay separates by TEM and XRD are the same order of magnitude, although the difference between mean values obtained on the clay separate of sample A416 by the two methods is relatively large. Nevertheless, it is clear that differences in values obtained from TEM and XRD analyses of clay
Volume-weighted thickness distributions of illite crystallites in rock samples
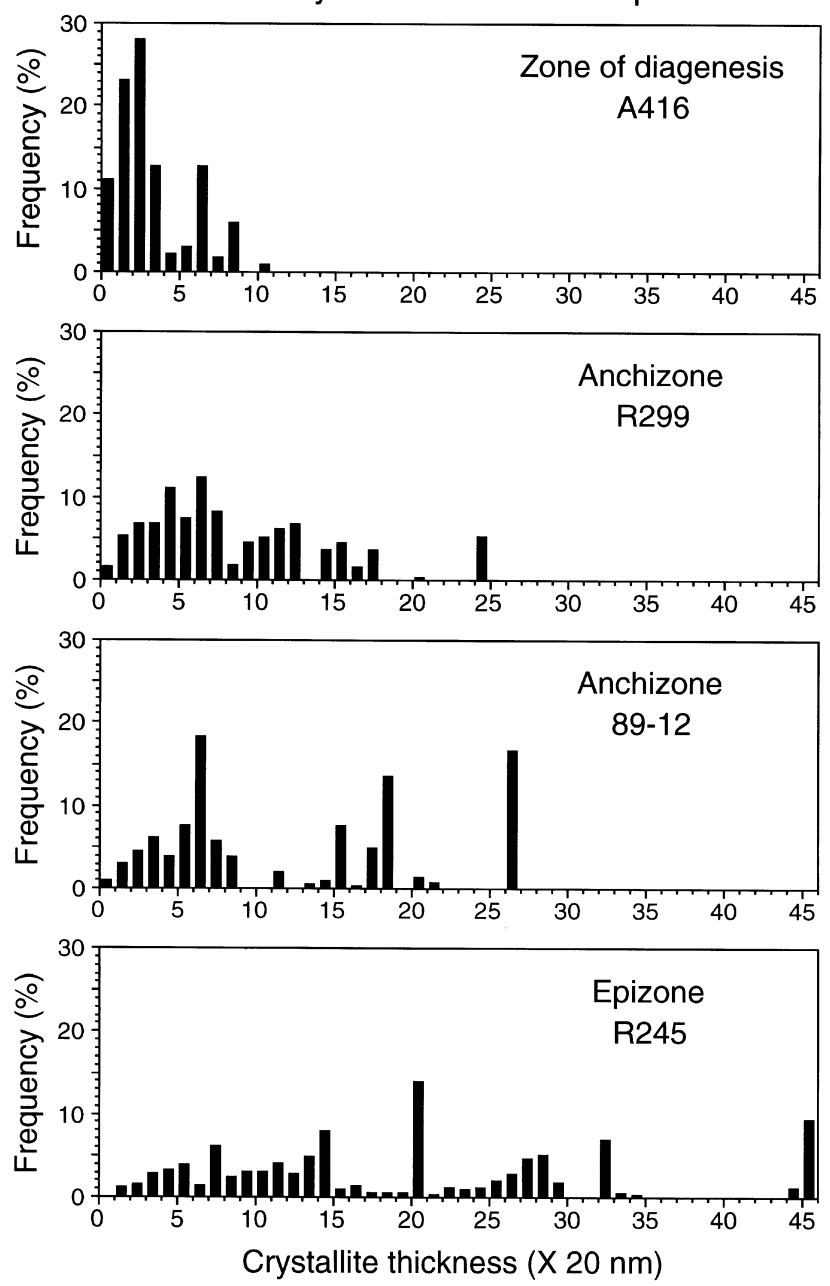

Fig. 14. Histogram showing the distributions of the thicknesses of illite crystallites in the ion-milled samples of pelitic rocks from the Gaspé Peninsula.

separates are small compared to differences relative to those measured on rock samples (Table 2). There are small differences between values determined from XRD profiles of air-dried and glycolated specimens of the same sample, probably because of the presence of small proportions of mixed layers and differences in background signals. Nevertheless, the XRD-determined mean crystallite size increases with increasing metamorphic grade, consistent with the trend determined by TEM.

\section{DISCUSSION}

\section{Prograde evolution}

The quantitative data presented above demonstrate that crystal size increases and defect density decreases progressively for illite as the degree of diagenesis and 
Table 2. Comparison of average crystallite size and square root of mean square strain of illite in selected pelitic rocks from the Gaspé Peninsula determined by TEM measurements and X-ray peak profile analyses.

\begin{tabular}{|c|c|c|c|c|}
\hline & A416 & R299 & 89-12 & $\mathrm{R} 245$ \\
\hline \multicolumn{5}{|c|}{ TEM measurements of illite in selected rock samples } \\
\hline Number of measured domains & 1777 & 1654 & 1278 & 581 \\
\hline Volume-averaged crystallite size $(\mathrm{nm})$ & 66.6 & 176.1 & 253.4 & 399.4 \\
\hline SQRT of mean square strain (\%) & 0.47 & 0.10 & 0.11 & 0.02 \\
\hline \multicolumn{5}{|c|}{ TEM measurements of illite in selected clay separates } \\
\hline Number of measured domains & 98 & 111 & 96 & 29 \\
\hline Volume-averaged crystallite size ( $\mathrm{nm})$ & 42.6 & 38.5 & 46.6 & 81.1 \\
\hline \multicolumn{5}{|c|}{ XRD profile analysis of $1 \mathrm{~nm}$ reflections of air-dried samples } \\
\hline Average crystallite size (nm) & 13.9 & 27.3 & 29.4 & 66.5 \\
\hline SQRT of mean square strain (\%) & 1.79 & 0.83 & 0.96 & 0.36 \\
\hline \multicolumn{5}{|c|}{ XRD profile analysis of $1 \mathrm{~nm}$ reflections of glycol-solvated samples } \\
\hline Average crystallite size $(\mathrm{nm})$ & 18.5 & 27.3 & 27.8 & 62.9 \\
\hline SQRT of mean square strain (\%) & 1.77 & 0.92 & 1.06 & 0.4 \\
\hline
\end{tabular}

low-grade metamorphism increases in the Gaspé samples. The overall changes and the orders of magnitude of crystallite sizes and lattice strains derived from the two independent methods are remarkably similar in spite of the limitations and assumptions in our approach. Although our analysis is based in part on approximations to complex functions as noted above, the reasonable and consistent values for both crystallite size and lattice strain imply that those approximations are warranted.

The observations of this study are consistent with the generally recognized prograde evolution of clay minerals. Growth of larger crystals and decrease in proportions of crystal defects are consistent with a decrease in the total free energy of a rock system that approaches a state of stable equilibrium. Such a process is associated with chemical changes of dioctahedral clay minerals from illitic to muscovitic compositions (associated with neoformation along cleavage in the epizonal rocks) (Jiang \& Peacor, 1994b), structural changes from $1 M_{\mathrm{d}}$ to $2 M_{1}$ polytypes (Hesse \& Dalton, 1991; this study), and microstructural changes. The Gaspé illite displays the following progressive microstructural features. (1) The diagenetic illite is characterized by relatively random crystal orientations but with preferred orientation parallel to bedding, small crystal sizes, a high proportion of stacking faults, layers commonly incoherently related, and relatively high densities of dislocations. (2) The anchizonal illite occurs in two textural types, one representing residual authigenic illite and the other 'metamorphic' illite. The latter has larger crystal sizes, generally coherent layer interfaces, and a low density of stacking faults, with preferential orientation parallel to the cleavage. (3) The epizonal illite is characterized by relatively defect-free, large crystals with sharply-defined boundaries that separate subparallel or interlocking crystals.

The processes by which crystal growth occurs will
Volume-weighted thickness distributions of illite crystallites in clay separates
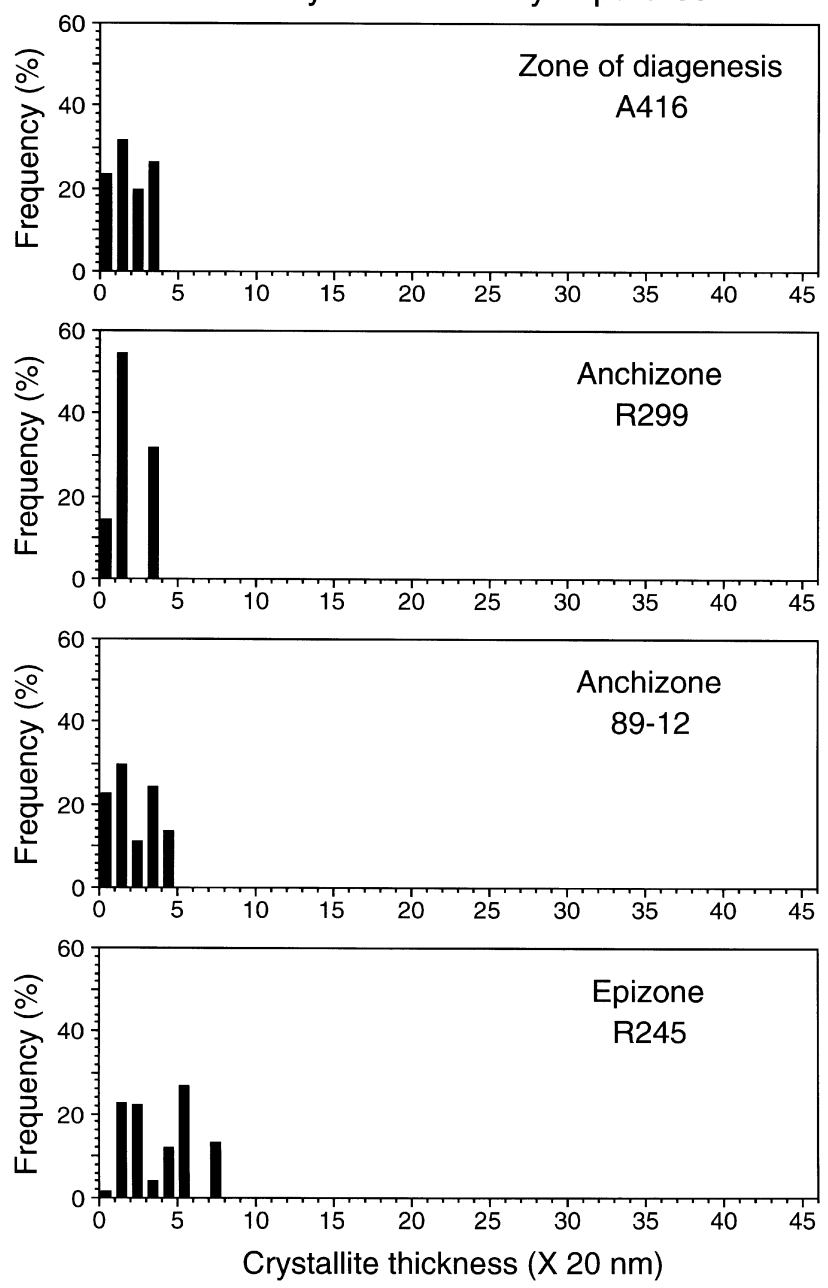

Fig. 15. Histogram illustrating the proportions of various thicknesses of illite crystallites in the clay separates of pelitic rocks from the Gaspé Peninsula.

be discussed in detail in a subsequent paper. We note here only that the features described above are consistent with a process of dissolution and neocrystallization in which the small crystals of relatively disordered $1 M_{\mathrm{d}}$ illite that formed during diagenesis progressively gave way to larger crystals of $2 M_{1}$ muscovite. The resulting arrays of highly strained, subparallel and partially coalesced packets were then replaced by defect-free larger crystals, through processes that at least in part involve lateral coalition of crystals through migration of dislocations parallel to layers, with only local dissolution and recrystallization focused at such defects. Such a process is based on the interaction of tectonically induced strain and dissolution, as has been demonstrated for the production of slaty cleavage in the shale-to-slate transition at Lehigh Gap, Pennsylvania (Lee et al., 1986; Ho et al., 1995). 


\section{Relation of illite microstructure to the illite crystallinity index}

The mean crystallite sizes independently determined from TEM and XRD analyses on the same clay separates are similar in magnitude (Table 2). Although the average difference in values is $c .20 \mathrm{~nm}$, the overall trends with increase in grade for both kinds of values are surprisingly similar, especially given the assumptions in both methods. We therefore conclude that our peak profile analysis, which also included values of strain, yields meaningful results. In addition, the crystallite-size values determined using peak halfheight widths as a variable in the Scherrer equation (Table 3) are similar to those obtained from TEM and profile analysis. This is remarkable in part as the Scherrer equation is an approximation that assumes that mean crystallite thickness is the only variable affecting peak half-width, i.e. there are no contributions from strain and size distributions.

Values of mean square strain, as determined independently by measurements of TEM images of ion-milled samples and by peak profile analysis, show similar general trends, decreasing with increasing grade. Absolute values are significantly different. This is not surprising, as strain was approximated in images of ion-milled samples only with layer terminations. This was the only easily measured parameter, but is clearly only one of several, which is consistent with the smaller TEM-determined strain values. However, these results are consistent with a general trend towards a decrease in strain with increasing grade, with densities of all kinds of defects decreasing similarly, even though only one kind was measured.

These data show that strain can clearly be determined by peak profile analysis as at least an order-ofmagnitude measure of true strain, and certainly contributes to peak half-height width. Nevertheless, the approximate correlations between mean crystallite sizes, as determined by peak profile analysis, TEM measurements and the Scherrer equation, collectively demonstrate that IC is almost entirely a measure of

Table 3. Average crystallite thickness of illite in the pelitic rocks from the Gaspé Peninsula by the Scherrer equation. ${ }^{1,2}$

\begin{tabular}{|c|c|c|c|c|c|c|}
\hline & \multirow[b]{2}{*}{ A416 } & \multirow[b]{2}{*}{ R299 } & \multirow[b]{2}{*}{$89-12$} & \multirow[b]{2}{*}{$\mathrm{R} 245$} & \multicolumn{2}{|c|}{$\begin{array}{l}\text { Anchizone } \\
\text { limits }\end{array}$} \\
\hline & & & & & low & high \\
\hline Half-height width, B ( $\left.{ }^{\circ} D 2 h\right)$ & 0.58 & 0.36 & 0.29 & 0.20 & 0.38 & 0.21 \\
\hline Instrumental broadening, $\mathrm{b}\left({ }^{\circ} \mathrm{D} 2 \mathrm{~h}\right)$ & 0.07 & 0.07 & 0.07 & 0.07 & 0.07 & 0.07 \\
\hline $\mathrm{b} / \mathrm{B}$ & 0.12 & 0.19 & 0.24 & 0.35 & 0.18 & 0.32 \\
\hline $\mathrm{b} / \mathrm{B}$ & 0.96 & 0.91 & 0.87 & 0.76 & 0.92 & 0.79 \\
\hline$b\left({ }^{\circ} D 2 h\right)$ & 0.56 & 0.33 & 0.25 & 0.15 & 0.35 & 0.17 \\
\hline Average crystallite size $(\mathrm{nm})$ & 14.1 & 24.0 & 31.7 & 53.3 & 22.7 & 47.8 \\
\hline
\end{tabular}

${ }^{1}$ Sherrer equation: $T=K \mid / b \cos h$ where $K=0.89, h=4.42^{\circ}, \mid=0.15418 \mathrm{~nm}$, and $b$ is in radians. Instrumental broadening is removed using the correction curve in fig. $9-9$ of Klug \& Alexander (1974). The samples are air-dried and oriented $<2 \mathrm{~mm}$ fractions. The values of the illite crystallinity indices for the diagenetic zone/anchizone and anchizone/epizone boundaries are taken from Kisch (1990).

${ }^{2}$ Calculation is based on data obtained from air-dried samples. crystallite size, providing that there is no contribution from swelling layers. This is remarkable in that inaccurate values are caused by several factors, including approximations in model functions, failure to account for strain, inaccurate removal of the instrumental broadening function, and inappropriate use of modelled profile forms to various functions. This is not to say that lattice strain cannot be a controlling factor of IC in samples of other sequences, for example where tectonic stress is especially significant. However, in normal prograde regional metamorphic sequences strain seems to have a minimal influence on the magnitude of IC (Fig. $16 \&$ references therein).

We are primarily concerned, however, not with the dimensions of crystallites in laboratory-prepared samples, but with their states in the rocks from which separates for XRD study are obtained. The crystallite sizes obtained by the analysis of TEM images of ionmilled samples are approximately five times greater than those of other analyses. Incipient cleavages were observed in separates studied by TEM, grains appeared to be bounded by cleavages in most cases, and densities of layer terminations were much smaller, consistent with preferential cleavage along strained planes. These relations imply that although IC is primarily a measure of crystallite size in separates, it can be a poor quantitative measure of true crystallite size in rock samples. The process of separation, in part influenced by local microstructures, may cause XRD-determined crystallite sizes to be considerably smaller than those in rock samples.
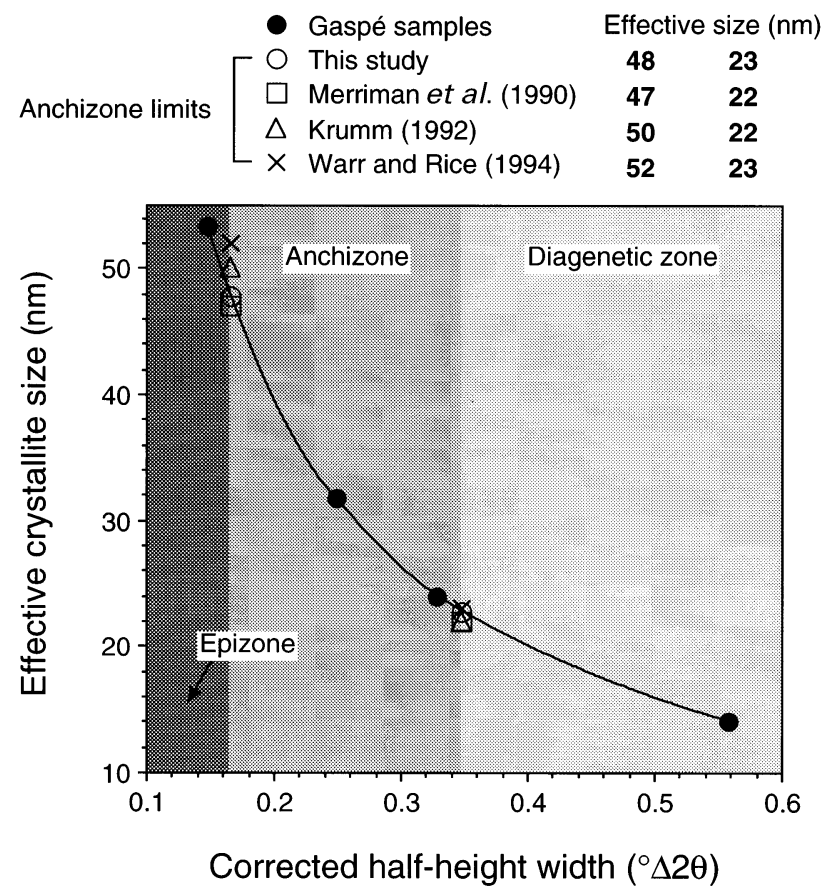

Fig. 16. Diagram showing the size limits of illite crystallites for the anchizone determined by this work and three other studies for different rock sequences. The incorporated half-height widths have been corrected for instrumental broadening. 
The limits of the anchizone (Table 3; Fig. 16) correspond to crystallite sizes of c. $27.7 \mathrm{~nm}$ and c. $47.8 \mathrm{~nm}$ based on the Scherrer equation, remarkably consistent with the values determined by Merriman et al. (1990), Krumm (1992) and Warr \& Rice (1994). We conclude that such excellent correlation is the result of similar methods and assumptions, the use of similar standards (or equivalents), the same general techniques, and appropriate instrumental settings and corrections in all cases. The consistency of these values obtained on several different sequences further implies that crystallite size is the dominant factor determining IC indices of pelitic rocks. These relations suggest that the IC correlates positively with the increase in crystal size and extent of dissolution and crystallization that are in turn related to metamorphic grade in regionally metamorphosed rocks. The degree of diagenesis and metamorphism may be estimated on a relative basis if the physical and chemical properties of rocks do not change dramatically and if metamorphic variables have acted in similar ways, i.e. for pelites that have undergone regional metamorphism.

Peacor (1992) noted that all factors that contribute to peak broadening (heterogeneity in composition and structure, crystal size and strain) must behave in a similar way as a function of grade. The illite that forms during diagenesis as a product of the reaction of smectite is the initial material in a prograde sequence for which the Ostwald step rule is the dominant principle (Essene \& Peacor, 1995). Insofar as small crystal sizes, high defect densities, and heterogeneity all represent states of disorder, the effect of all three variables must diminish in a regular way as metamorphic grade increases and a state of stable equilibrium is approached. IC measured on clay separates of a given rock may not represent the microstructural state of the illite in the rock, but it does satisfactorily reflect the trend of variations of microstructures, degree of recrystallization, or metamorphic grade. The microstructural changes caused by rock disintegration in the preparation of clay separates are likely a function of peak-broadening variables such as mixed layering, crystallite size and lattice strain as well.

\section{Concerns, precautions and suggestions}

\section{Variations in layer spacings}

Heterogeneity can occur in otherwise coherent diffracting units through both variation in composition and mixed layering, a factor that is generally not considered in derivations of peak broadening functions. Illite is generally heterogeneous in composition (Peacor, 1992), resulting in variations in $d$-values, which cause broadening of the $00 \mathrm{l}$ reflections of illite. Even near-stoichiometric muscovite may exhibit variable spacings due to the common substitution of $\mathrm{Na}$ for interlayer K (e.g. Guidotti et al., 1992), although there is no evidence to suggest that the resultant variation in the spacing of basal planes of K-dominant illite is significant in relation to factors such as crystallite size or strain. The $\mathrm{Na}$ content of all white micas determined in this study is small (generally $<5 \%$ of the total interlayer charge) and therefore the effect is negligible for our samples, but may need to be considered in other samples and for more detailed, comprehensive and precise analyses. Mixed layering of other species may also occur, giving rise to diffuseness parallel to $c^{*}$ in stacks that act as coherent scattering units. A variety of mixed-layer species has been observed, but, as discussed above, smectite-like layers are the most common mixed-layered components in diagenetic rocks. They may contribute to peak width and shape, as suggested by Eberl \& Srodon (1988) and Eberl \& Velde (1989). Where variation of spacing caused either by mixed layering or heterogeneity in composition occurs to a significant degree, the convolution of those functions must be separately analysed, as for the strain and crystallite size functions, because otherwise their contributions will be included within 'strain' or 'size' values.

\section{Variations in the form of crystallite size distributions}

A critical question is concerned with the relation between mean crystallite size and the form of the size distribution. The effect of crystallite size on the XRD peak profile is due to the convolution of the full crystallite size distribution. Where crystallite size distributions of a prograde sequence increase smoothly and continuously and where there is only one mode of occurrence of illite, the calculation of mean values may correctly reflect simple size functions. However, as in the samples of this study, which are transitional, two entirely separate (e.g. neoformation and recrystallization or crystal growth) modes of illite may occur, each having a different distribution. This in part reflects modes that form in response to Ostwald steps, rather than simple ripening. The occurrence of a detrital component, for which crystals in rocks normally exceed sizes that influence peak breadth, but which may be cleaved during separation, is also significant. Peak profiles may thus give rise to similar mean crystallite sizes, but reflect very different size distributions. This study has shown that similar mean values were determined by the XRD profile analysis and TEM methods, but that each sample displays a wide range of size distributions. Values of mean crystallite sizes may be less significant than is now apparent, and it is therefore essential in future studies that the convolutions of complete size distributions and lattice strain functions be carried out in order to obtain a more precise correlation between full peak profiles and the microstructural states of illite crystals. It may thus be possible to quantitatively determine, or at least constrain, the complete crystallite size and lattice strain functions to peak profiles and then to relate the more simple IC index to those functions. 


\section{Artefacts of the specimen preparation process}

This study has demonstrated remarkably similar results between TEM and XRD measurements on clay separates. However, different specimen preparation methods may yield different results, and standardization of separation techniques, as recommended by several authors (e.g. Warr \& Rice, 1994) is essential. Some diminishment in size must occur during separation by cleavage on $\{001\}$. Such changes in crystallite size assumedly vary with severity and kind of treatment, and sample features such as proportions of mixed layers and layer coherency. The relations between crystallite size distributions in corresponding rocks and separates prepared with various methods has yet to be firmly established.

\section{Greater precision of TEM-determined values}

Although this study has demonstrated a quantitative direct relation between TEM-determined parameters and those determined by XRD, those results are of 'first order'. The measurement of crystallite thicknesses and defect densities is an extremely time-consuming, non-automated process where individual crystals are divided into zones, as must be done where accurate values are required. Although extensive, the dataset obtained in this study should eventually be significantly expanded to improve precision. In order to further verify that boundaries between independent diffracting domains have been properly defined, much TEM work remains to be carried out for typical examples. Strain determined through layer terminations in this study serves as a practical approximation to total strain. Nevertheless, other contributions to strain, that can be precisely determined only with great difficulty, must ultimately be determined quantitatively.

The ultimate test of the correspondence between XRD-measured peak profiles and the detailed characterization of the microstructural states of illite in rock samples will occur when all structural state functions that affect XRD peak profiles have been completely defined and XRD peak profiles can be accurately reproduced through calculations that yield the convolution of those functions with the diffractometer-systemproduced profiles.

\section{ACKNOWLEDGMENTS}

R. Hesse is especially thanked for providing all samples and much supporting information. We acknowledge N.-C. Ho for his help in computing. We are also grateful to D. D. Eberl, E. J. Essene, B. A. van der Pluijm, B. Roberts and L. M. Walter for their constructive reviews. This work was supported by NSF grants EAR-88-17080 and EAR-91-04565 to DRP, grant 85-0501-I-006-097-A from the National Science Council of the Republic of China to WTJ, and grant T-007211 from the National Science Fundation of Hungary (OTKA, Budapest) to PA. The scanning transmission electron microscope used in this work was acquired under NSF grant EAR-87-08276.

\section{REFERENCES}

Ahn, J. H. \& Peacor, D. R., 1986. Transmission and analytical electron microscopy of the smectite-to-illite transition. Clays and Clay Minerals, 34, 165-179.

Aldahan, A. A. \& Morad, S., 1986. Mineralogy and chemistry of diagenetic clay minerals in Proterozoic sandstones from Sweden. American Journal of Science, 286, 29-80.

Árkai, P. \& Tóth, M. N., 1983. Illite crystallinity: combined effects of domain size and lattice distortion. Acta Geologica Hungarica, 26, 341-358.

Árkai, P., Merriman, R. J., Roberts, B., Peacor, D. R. \& Tóth, M. N., 1996. Crystallinity, crystallite size and lattice strain of illite-muscovite and chlorite: comparison of XRD and HRTEM data for diagenetic to epizonal pelites. European Journal of Mineralogy, 8, 1119-1137.

Bons, A.-J., 1988. Deformation of chlorite in naturally deformed low-grade rocks. Tectonophysics, 154, 149-165.

Brindley, G. W. \& Brown, G., 1984. Crystal Structures of Clay Minerals and Their X-ray Identification. Mineralogical Society, London.

Buerger, M. J., 1960. Crystal-structure Analysis. Wiley, New York, NY

de Keijser, Th. H., Langford, J. I., Mittemeijer, E. J. \& Vogels, A. B. P., 1982. Use of the Voigt functions in a single-line method for the analysis of X-ray diffraction line broadening. Journal of Applied Crystallography, 15, 308-314.

Delhez, R., de Keijser, Th. H. \& Mittemeijer, E. J., 1982. Determination of crystallite size and lattice distortions through $\mathrm{X}$-ray diffraction line profile analysis. Fresenius Zeitschrift für Analytische Chemie, 312, 1-16.

Eberl, D. D. \& Srodon, J., 1988. Ostwald ripening and interparticle-diffraction effects for illite crystals. American Mineralogist, 73, 1335-1345.

Eberl, D. D., Srodon, J., Kralik, M., Taylor, B. E. \& Peterman, Z. E., 1990. Ostwald ripening of clays and metamorphic minerals. Science, 248, 474-477.

Eberl, D. D. \& Velde, B., 1989. Beyond the Kübler index. Clay Minerals, 24, 571-577.

Essene, E. J. \& Peacor, D. R., 1995. Clay mineral thermometry - a critical perspective. Clays and Clay Minerals, 43, 540-553.

Flehmig, W. \& Langheinrich, G., 1974. Beziehung zwischen tekonischer Deformation und Illite-Kristallinität. Neues Jahrbuch für Geologie und Paläontologie, Abhandlungen, 146, 325-326.

Frey, M., 1987. Very low-grade metamorphism of clastic sedimentary rocks. In: Low Temperature Metamorphism. (ed. Frey, M.), pp. 9-58. Blackie, Glasgow.

Frey, M., Hunziker, J. C., Roggwiller, P. \& Schindler, C., 1973. Progressive niedriggradige Metamorphose glaukonitführender Horizonte in den helvetischen Alpen der Ostschweiz. Contributions to Mineralogy and Petrology, 39, 185-218.

Grubb, S. M. B., Peacor, D. R. \& Jiang, W.-T., 1991. Transmission electron microscope observations of illite polytypism. Clays and Clay Minerals, 39, 540-550.

Guidotti, C. V., Mazzoli, C., Sassi, F. P. \& Blencoe, J. G., 1992. Compositional controls on the cell dimensions of $2 M_{1}$ muscovite and paragonite. European Journal of Mineralogy, 4, 283-297.

Guinier, A., 1963. X-ray Diffraction in Crystals, Imperfect Crystals and Amorphous Bodies. Freeman, San Francisco.

Hesse, R. \& Dalton, E., 1991. Diagenetic and low-grade metamorphic terrains of Gaspé Peninsula related to geologic structure of the Taconian and Acadian orogenic belts, Quebec Appalachians. Journal of Metamorphic Geology, 9, 775-790.

Ho, N.-C., van der Pluijm, B. A. \& Peacor, D. R., 1995. Reorientation mechanisms of phyllosilicates in the mudstone- 
to-slate transition at Lehigh Gap, Pennsylvania. Journal of Structural Geology, 17, 345-356.

Inoue, A., Velde, B., Meunier, A. \& Touchard, G., 1988. Mechanism of illite formation during smectite-to-illite conversion in a hydrothermal system. American Mineralogist, 73, $1325-1334$.

Islam, S. \& Hesse, R., 1983. The P-T conditions of late-stage diagenesis and low grade metamorphism in the Taconic belt of the Gaspé Peninsula from fluid inclusions: preliminary results. Geological Survey of Canada, Current Research, Part B, Paper, 83-1B, 145-150.

Islam, S., Hesse, R. \& Chagnon, A., 1982. Zonation of diagenesis and low-grade metamorphism in Cambro-Ordovician flysch of the Gaspé Peninsula, Quebec Appalachians. The Canadian Mineralogist, 20, 155-167.

Jiang, W.-T. \& Peacor, D. R., 1991. Transmission electron microscopic study of the kaolinitization of muscovite. Clays and Clay Minerals, 39, 1-13.

Jiang, W.-T. \& Peacor, D. R., 1994a. Prograde transitions of corrensite and chlorite in low-grade pelitic rocks from the Gaspé Peninsula, Quebec. Clays and Clay Minerals, 42, 497-517.

Jiang, W.-T. \& Peacor, D. R., 1994b. Formation of corrensite, chlorite, and chlorite-mica stacks by replacement of detrital biotite in low-grade pelitic rocks. Journal of Metamorphic Geology, 12, 867-884.

Kisch, H. J., 1987. Correlation between indicators of very lowgrade metamorphism. In: Low Temperature Metamorphism. (ed. Frey, M.), pp. 227-300. Blackie, Glasgow.

Kisch, H. J., 1990. Calibration of the anchizone: a critical comparison of illite 'crystallinity' scales used for definition. Journal of Metamorphic Geology, 8, 31-46.

Kisch, H. J., 1991. Illite crystallinity: recommendations on sample preparation, X-ray diffraction settings, and interlaboratory samples. Journal of Metamorphic Geology, 9, 665-670.

Klug, H. P. \& Alexander, L. E., 1974. X-ray Diffraction Procedures for Polycrystalline and Amorphous Materials, 2nd edition. Wiley, New York, NY.

Kodama, H., 1965. Crystal distortion of sericite. Clay Science, 2, 121-131.

Kodama, H., Gatineau, L. \& Mering, J., 1971. An analysis of $\mathrm{X}$-ray diffraction line profiles of microcrystalline muscovites. Clays and Clay Minerals, 19, 405-413.

Krumm, S., 1992. 'Illitkristallinität' als Indikator schwacher Metamorphose. Methodische Untersuchungen und Vergleiche mit anderen Parametern. Erlanger geologische Abhandlungen, 120, $1-75$

Kübler, B., 1967. La cristallinité de l'illite et les zones tout à fait supérieures du métamorphisme. In: Etages tectoniques, pp. 105-121, Colloque de Neuchâtel 1966. À La Bacounière, Neuchâtel, Suisse.

Langford, J. I., 1978. A rapid method for analysing the breadth of diffraction and spectral lines using the Voigt function. Journal of Applied Crystallography, 11, 10-14.

Lanson, B. \& Champion, D., 1991. The I/S-to-illite reaction in the late stage diagenesis. American Journal of Science, 291, 473-506

Lee, J. H., Ahn, J. H. \& Peacor, D. R., 1985. Textures in layered silicates: progressive changes through diagenesis and lowtemperature metamorphism. Journal of Sedimentary Petrology, 55, 532-540.

Lee, J. H., Peacor, D. R., Lewis, D. D. \& Wintsch, R. P., 1986. Evidence for syntectonic crystallization for mudstone to slate transition at Lehigh Gap, Pennsylvania, U.S.A. Journal of Structural Geology, 8, 767-780.

Merriman, R. J., Roberts, B. \& Peacor, D. R., 1990. A transmission electron microscope study of white mica crystallite size distribution in a mudstone to slate transitional sequence, North Wales, UK. Contributions to Mineralogy and Petrology, 106, 27-40.

Nieto, F. \& Sánchez-Navas, A., 1994. A comparative XRD and TEM study of the physical meaning the white mica 'crystallinity' index. European Journal of Mineralogy, 6, 611-621.

Nyk, R., 1985. Illite crystallinity in Devonian slates of the Meggen mine (Rhenish Massif). Neues Jahrbuch für Mineralogie, Monatshefte, 1985, 268-276.

Peacor, D. R., 1992. Diagenesis and low-grade metamorphism of shales and slates. In: Minerals and Reactions at the Atomic Scale: Transmission Electron Microscopy (ed. Buseck, P. R.), pp. 335-380. Mineralogical Society of America, Washington, DC.

Reynolds, R. C., 1989. Principles of powder diffraction. In: Modern Powder Diffraction (eds Bish, D. L. \& Post, J. E.), pp. 1-17. Mineralogical Society of America, Washington, DC.

Roberts, B. \& Merriman, R. J., 1985. The distinction between Caledonian burial and regional metamorphism in metapelites from North Wales: an analysis of isocryst patterns. Journal of the Geological Society, London, 142, 615-624.

Slack, J. F., Jiang, W.-T., Peacor, D. R. \& Okita, P. M., 1992. Hydrothermal and metamorphic berthierine from the Kidd Creek volcanogenic massive sulfide deposit, Timmins, Ontario. The Canadian Mineralogist, 30, 1127-1142.

St. Julien, P. \& Hubert, C., 1975. Evolution of the Taconian orogen in the Quebec Appalachians. American Journal of Science, 275-A, 337-362.

Teichmüller, M., Teichmüller, R. \& Weber, K., 1979. Inkohlung und Illit-Kristallinität-Vergleichende Untersuchungen im Mesozoikum und Paläozoikum von Westfalen. Fortschritte in der Geologie von Rheinland und Westfalen, 27, 201-276.

Warr, L. N. \& Rice, A. H. N., 1994. Interlaboratory standardization and calibration of clay mineral crystallinity and crystallite size data. Journal of Metamorphic Geology, 12, $141-152$.

Warren, B. E. \& Averbach, B. L., 1950. The effect of cold-work distortion on X-ray patterns. Journal of Applied Physics, 21, 595-599.

Weaver, C. E., 1960. Possible uses of clay minerals in search for oil. Bulletin of the American Association of Petroleum Geologists, 44, 1505-1518.

Weaver, C. E., 1961. Clay minerals of the Ouachita structural belt and the adjacent foreland. In: The Ouachita Belt (eds Flawn, P. T., Goldstein, A., King, P. B. \& Weaver, C. E.). University of Texas Publication, 6120, 147-160.

Whalen, J. B., 1985. The McGerrigle plutonic complex, Gaspé, Quebec: evidence of magma mixing and hybridization Geological Survey of Canada, Current Research, Part A, Paper, 85-1A, 795-800.

Williams, H. \& Hatcher, R. D., 1983. Appalachian suspect terranes. In: Contributions to the Tectonics and Geophysics of Mountain Chains (eds Hatcher, R. D., Williams, H. \& Zietz, I.), Geological Society America Memoir, 158, 33-53.

Wilson, A. J. C., 1962. On variance as a measure of line broadening in diffractometry. General theory and small particle size. Proceedings of the Physical Society, 80, 286-294.

Wilson, A. J. C., 1963a. On variance as a measure of line broadening in diffractometry. II: mistakes and strain. Proceedings of the Physical Society, 81, 41-46.

Wilson, A. J. C., 1963b. Mathematical Theory of X-ray Powder Diffraction. Philips Technical Library, New York, NY.

Received 12 April 1996; revision accepted 8 October 1996. 